\title{
Tirinhas em situações de ensino e o alcance do leitor
}

\section{Comic strips in teaching situations and reaching for the reader}

https://doi.org/10.34112/2317-0972a2016v34n66p75-92

Edilaine Buin ${ }^{1}$

Bianca Estefani Meneguini ${ }^{2}$

RESUMO: Este artigo é resultado da análise das propostas referentes à leitura de tirinhas em um $6^{\circ}$ ano de uma escola pública em Amambai-MS. Observando 73 tirinhas trabalhadas ao longo do ano, verifica-se quantitativamente que: (i) a maioria das atividades trata as tirinhas como gêneros discursivos, focalizando aspectos relevantes de leitura; (ii) a minoria é utilizada como pretexto para o ensino de gramática. Embora isso represente um quadro positivo, ainda se negligencia a questão da leitura em várias atividades. Na condução do uso do material didático, observa-se que se dedica maior tempo às atividades mais próximas da tradição gramatical, embora representem a minoria. Esse tipo de encaminhamento parece funcionar como clichê, lugar de esvaziamento dos sentidos. Fazer do aluno um leitor é estar diante da possibilidade de se perder, ao fugir do que é corriqueiro - risco do qual muitos se distanciam, apesar de duas décadas de orientações inovadoras nos documentos oficiais. PALAVRAS-CHAVE: Leitura; tiras; ensino de língua portuguesa.

ABSTRACT: This article is the result of the analysis of the proposals related to the reading of comic strips in a 6th grade public school in Amambai-MS. Analyzing 73 strips worked throughout the year, we have found quantitatively that: (i) most of the activities deal with

1. Universidade Federal da Grande Dourados, Dourados, MS, Brasil.

2. Universidade Federal da Grande Dourados, Dourados, MS, Brasil. 
strips as genres, focusing on relevant aspects of reading; (ii) the minority is used as a pretext for the grammar teaching. Although this represents a positive situation, it still neglects the issue of reading in various activities. We have observed that, whenever the teaching materials are used, a greater amount of time is dedicated to the activities which are closer to the grammatical tradition, although they represent a minority. This type of teaching seems to function as clichés, which are, in turn, empty of meaningful learning. Making the student a reader is facing the possibility of losing oneself to escape from what is commonplace - a risk that many drift away from, despite two decades of innovative guidance in official documents. KEYWORDS: Reading; strips; portuguese language teaching.

[...] Suas palavras não machucam porque não foram pensadas para ferir. Com a ponta dos dedos, elas acariciam. Foram pronunciadas para dar uma chance ao interlocutor, leitor. São como uma mão que alcança - e não um pé que esmaga. Vivemos num mundo em que as pessoas se sentem mais seguras quando se tornam pés que esmagam. A mão que alcança exige mais coragem, porque alcançar é sempre um risco - e esmagar tem um final previsível.

Eliane Brum, 2013

\section{INTRODUÇÃO}

Nas últimas décadas, desde a publicação dos Parâmetros curriculares nacionais (PCN), em 1998, tanto as escolas quanto os materiais didáticos do ensino básico têm voltado a atenção para os gêneros discursivos como eixo do trabalho em Língua Portuguesa, devido às diversas demandas por inovação (SIGNORINI, 2007), além das pressões vindas dos órgãos oficiais ligados à Educação. No entanto, nosso contato com algumas escolas ${ }^{3}$ e com materiais didáticos por elas adotados tem mostrado que, na prática, pouco mudou. Ao ser didatizado, o gênero perde a sua função social e, sob novo rótulo, prevalece o mesmo trabalho de sempre, informado pela tradição gramatical. Desconsiderar usos e situações de produção pode significar perder a oportunidade de promover o desenvolvimento da leitura e da escrita dos alunos. Ou, o que é mais

3. Nosso contato com as escolas ocorre em função do subprojeto vinculado ao Programa Institucional de Iniciação à Docência (PIBID), Leitura, oralidade, escrita e reescrita, vinculado ao curso de Letras da Universidade Federal da Grande Dourados (UFGD); e também com as escolas de Dourados e região, em virtude do Estágio Supervisionado dos alunos do $4^{\circ}$ ano/2014. 
grave, pode reduzir os diversos textos, tão produtivos socialmente, a tarefas que só fazem sentido (se o fazem!) nos limites dos muros escolares.

Visando a um ensino de mais qualidade, o Programa Nacional do Livro Didático (PNLD) do Ministério da Educação (MEC), avalia, por meio de equipes de pareceristas especializados, as obras submetidas pelas editoras, e publica um guia com as coleções consideradas aprovadas. As escolas selecionam, dentre os aprovados, aqueles que atendem ao seu projeto pedagógico ${ }^{4}$. As avaliações tomam por base as orientações dos Parâmetros curriculares nacionais (PCN), que prezam o gênero como eixo de trabalho, aproximando-se também de uma abordagem funcional da gramática (NEVES, 2013), em detrimento de uma abordagem tradicional, guiada por tópicos da gramática tradicional. Os PCN (BRASIL, 1997, 1998) priorizam uma abordagem assistemática da gramática, uma vez que os conteúdos devem ser abordados de acordo com as necessidades apresentadas pelos alunos em função das atividades de produção, leitura e escuta dos textos (BUIN, 2004).

O livro didático do $6^{\circ}$ ano (CEREJA; MAGALHÃES, 2009) adotado por uma escola pública de Amambai-MS ${ }^{5}$, do qual foram retiradas as tirinhas ${ }^{6}$ aqui analisadas, foi escolhido pelos professores entre aqueles aprovados pelo PNLD. Este artigo é resultado da análise das atividades propostas referentes à leitura de tirinhas. Na ocasião em que escolhemos observar com atenção esse livro, acompanhávamos uma pesquisa paralela ${ }^{7}$ que buscava compreender as escritas de alguns alunos dessa série, consideradas muito "problemáticas" por seus professores. O livro era seguido fielmente pela professora de Língua Portuguesa, participante das pesquisas em andamento, de modo que investigar a maneira pela qual o livro conduzia as atividades de leitura significava recuperar parcialmente como era conduzido o trabalho em sala de aula. Buscávamos capturar todos os elementos contextuais que pudessem contribuir, ainda que muito indiretamente, com os resultados insatisfatórios das escritas dos alunos.

4. Disponível em: <http://portal.mec.gov.br>.

5. Essa escola foi escolhida pela facilidade de contato direto com seus professores de Língua Portuguesa e coordenadores, o que nos possibilitou, consequentemente, o acesso a informações relevantes para a pesquisa.

6. Segundo Mendonça (2008), as tiras (que chamamos de tirinhas, seguindo o nome usado pela comunidade escolar) se distinguem das histórias em quadrinhos (HQs), por serem curtas, contando com três quadros geralmente (podendo chegar a cinco). E, em razão de sua curta extensão, podem ser publicadas em suportes variados. As histórias em quadrinhos, uma sequência de narrativas maiores, constituem espaços próprios para publicação, passando a circular em revistas específicas - "gibis" e almanaques.

7. Projeto Voluntário de Iniciação Científica (PIVIC) desenvolvido pela graduanda Patrícia Almeida Benites, em 2013 e 2014. 
O interesse principal, contudo, não se volta para o estudo do livro didático, o qual é aqui focado porque partimos da hipótese de que o modo como são conduzidas as atividades de leitura e de escrita em sala de aula pode ter algum tipo de impacto na forma como são construídos os textos pelos alunos. Nosso foco, portanto, está na condução que é dada à leitura do aluno em sala de aula, a qual representa um todo de grau elevado de complexidade, composto de vários elementos, que vão desde materiais socioideologicamente situados, condução de atividades, sujeitos ali envolvidos e suas histórias singulares. Assim, para tentar entender melhor aquilo que o aluno apresenta como resultado insatisfatório, em relação à habilidade de ler e de escrever, é necessário compreender alguns vieses do contexto do qual esse sujeito "escrevente/leitor" faz parte.

Ao trabalhar os gêneros discursivos veiculados pelo livro aprovado pelo PNLD, a professora acreditava seguir as orientações oficiais, ou seja, fazia do gênero seu principal instrumento de trabalho, embora pudéssemos observar que o tempo maior sempre era dedicado aos modos tradicionais de trabalho. Em alguns momentos, atribuía o fato de os alunos não apresentarem bons resultados ao excesso de atividades "alternativas", as quais não focavam aspectos da gramática tradicional. Isso nos permite remeter à situação em que ficam os autores, diagramadores, ilustradores etc., os quais, ao mesmo tempo em que devem seguir as orientações curriculares oficiais, não podem se distanciar drasticamente daquilo que os professores almejam e acreditam ser produtivo.

O interesse era investigar como o livro conduz o trabalho de leitura dos gêneros. As tirinhas aparecem em maior quantidade na coleção, estando presentes em todas as seções do material ("Estudo do texto" "Produção de texto", "Para escrever com adequação/coerência/coesão/expressividade", "A língua em foco", "De olho na escrita"), o que nos levou a delimitar nosso olhar para elas neste momento da pesquisa. Essa presença marcante deve-se possivelmente ao fato de que as histórias em quadrinhos foram gêneros ausentes na tradição do ensino normativo, e agora marcam a modernidade: dão um colorido ao livro (portanto, mais chances de aprovação pelo PNLD), o que o coloca em um lugar mais distante dos manuais de gramática normativa que não seguem as orientações oficiais. Focalizar as tirinhas do LD pode ser comparado a prestar atenção em um só instrumento, quando se escuta um concerto. Do mesmo modo que um instrumento de corda pode perpassar toda a melodia, as tirinhas perpassam todo o material. $\mathrm{O}$ som do violino, por exemplo, pode ser capturado ao longo da melodia; as tirinhas percorrem todo o LD. 
Para investigar como o material didático conduz a leitura das tiras, independentemente da seção da qual fazem parte, o trabalho iniciou-se por uma análise quantitativa dos dados. A partir da leitura das 73 tirinhas presentes no livro de 240 páginas, categorizamos cada atividade a elas associadas pelo modo como o LD aborda o gênero em questão. Em seguida, baseados em uma análise qualitativa, selecionamos cinco propostas representativas do que desejamos mostrar, isto é, a condução da leitura de tirinhas em sala de aula. Antes das análises, discorreremos brevemente sobre o gênero discursivo no ensino de Língua Portuguesa e, mais especificamente, sobre a tirinha.

\section{O GÊNERO DisCURSIVO NO ENSINO DE LÍNGUA PORTUGUESA}

Os Parâmetros curriculares nacionais (BRASIL, 1998) chamam a atenção para a mudança necessária no que se refere ao ensino de língua materna, focada em um ensino que estabeleça mediação com a vida cotidiana dos sujeitos, e não mais restrito ao ambiente escolar, tomando por objeto de estudo os gêneros discursivos. Conforme Bakhtin (2003 [1992]), a língua se efetua através de enunciados (orais e escritos), que refletem as condições específicas e as finalidades de cada campo através do tema, o modo composicional (a estrutura) e o estilo (usos específicos da língua). Segundo ele:

[...] Toda compreensão da fala viva, do enunciado vivo é de natureza ativamente responsiva (embora o grau desse ativismo seja bastante diverso); toda compreensão é prenhe de resposta, e nessa ou naquela forma a gera obrigatoriamente: o ouvinte se torna falante. [...] (Bakhtin, 2003, p. 271 [1992]).

Fiorin (2006, p. 61) explica didaticamente as palavras de Bakhtin, ao dizer que "o gênero estabelece uma interconexão da linguagem com a vida social. A linguagem penetra na vida por meio dos enunciados concretos, e ao mesmo tempo, são pelos enunciados que a vida se introduz na linguagem". Em toda esfera de comunicação oral e escrita, existem e são empregados os gêneros, que são ilimitados, demarcados por uma função específica para cada campo de utilização da língua (científica, técnica, publicística, oficial e cotidiana).

Essas palavras chamam a atenção para a relevância das orientações curriculares para o ensino de língua portuguesa segundo a perspectiva dos gêneros discursivos 
(BRASIL, 1998). Todo gênero nasce da necessidade de interlocução, o que deveria ser sempre considerado ao trabalhar com texto na sala de aula. Focar o ensino nos gêneros discursivos (e não nos tópicos da gramática tradicional) significa priorizar o desenvolvimento da expressão escrita e oral do aluno e de sua capacidade leitora, determinante para seu posicionamento crítico na vida futura. Na troca interlocutiva, o professor é também beneficiado, à medida que, ao ter de ensinar, avança na leitura dos gêneros que o circulam, para além do superficial, fazendo relações da palavra escrita com a vida, com o meio, com a cultura.

Em relação ao ensino médio, até há pouco tempo, a preocupação em trabalhar com tipos tradicionais textuais (narração, descrição e dissertação) esteve relacionada à preparação dos alunos para o vestibular. Por isso, sempre foram levados em consideração fatores estruturais e gramaticais para a construção da redação. O que ocorre é que as tipologias têm um caráter limitado e desvinculado da realidade dos sujeitos, abrangendo apenas o contexto escolar. Daí a importância do trabalho com gêneros discursivos, que pressupõem as práticas sociais.

Para trabalhar a leitura e escrita em sala de aula, deve-se considerar quem produz o texto, qual o interlocutor, qual é a finalidade do texto e que gênero pode ser utilizado para que a comunicação atinja plenamente seu objetivo. $O$ gênero deve funcionar como megainstrumento (SCHNEUWLY; DOLZ, 2004) para preparar os alunos para as diversas práticas de linguagem e para ajudá-los a compreender melhor a realidade. Quando isso acontece, ainda que por meio de uma situação ficcional, os resultados parecem mais positivos.

O trabalho gramatical, por sua vez e nessa perspectiva, deve ser encaminhado para a prática reflexiva e do letramento crítico sobre a funcionalidade dos elementos linguísticos em diferentes gêneros, conforme postulamos em Buin (2004). Aproximando da abordagem funcional da gramática (NEVES, 2004), acredita-se que só é produtivo na escola um trabalho gramatical vinculado às tirinhas, se ele estiver a serviço de propiciar uma leitura mais madura, maior entendimento e conscientização das possibilidades que a língua oferece para manipular e construir os sentidos.

Dedicaremos a próxima seção às tirinhas.

\subsection{AS TIRINHAS E SUA RECONTEXTUALIZAÇÃo PARA O LD}

As tirinhas são um subtipo de histórias em quadrinhos (HQs), narrativas mais curtas que estes, formadas por imagens e palavras, organizadas em sequência de três 
a cinco quadrinhos (MENDONÇA, 2008). Podem caracterizar-se por apresentar humor ou crítica social, o que as leva a circular em vários suportes - jornais impressos e virtuais, revistas, livros didáticos -, alcançando público de todas as idades.

Recontextualizar a tirinha para o ensino de língua materna é direcionar os sujeitos a inferir, contextualizar, compreender, interpretar o humor, ironias, metáforas, paródias e implícitos, além de acionar referências culturais próprias do mundo dos adultos a partir do contexto evidenciado (MENDONÇA, 2008). Trabalhar com esse gênero - não somente para propiciar uma estética colorida e moderna ao LD - pode significar uma contribuição considerável para um ensino inovador, contextualizado com a realidade cotidiana dos sujeitos e voltado para a construção de um ser mais crítico e analítico.

Como dissemos, um dos gêneros em destaque no $\mathrm{LD}$ focalizado é a tirinha. Nas páginas finais, encontra-se o manual do professor, que tem o objetivo de explicar sua proposta didática, a qual prioriza a formação de leitores "para todos os tipos de textos, sob a perspectiva dos gêneros em circulação social” (CEREJA; MAGALHÃES, 2009, p. 3).

Cereja e Magalhães (2009, p. 3) salientam que sua proposta de trabalho é apoiada na teoria dos gêneros textuais, a fim de alargar os horizontes dos estudos da linguagem, cujo interesse é explorar "seja na condição de receptor, ou produtor outras linguagens, verbais ou não, como a pintura, a fotografia, o cinema, o cartum e etc". Os autores reforçam que o ensino de língua portuguesa deve abordar a leitura, a produção de textos e os estudos gramaticais sob a perspectiva da língua como ação e como interação social.

Com intuito de (re) apresentar o que é reconhecido ou autorizado como modo de conhecimento a respeito da linguagem e das formas de ensino-aprendizagem, os autores sugerem aos professores leituras teóricas do que seja o gênero discursivo, para que possam conduzir um melhor trabalho com seus alunos. Podemos assim dizer que essa obra vai ao encontro das discussões e dos estudos da teoria linguística. Nas referências bibliográficas, o material didático elenca os seguintes linguistas: Bakhtin (1997), Dionísio (2002), Machado (2004), Marcuschi (2004), Meurer (2005), Neves (2003), Rojo (2000), Schneuwly (2004), Todorov (1981).

No interior do LD, há variados gêneros. Porém, como dissemos, optamos, metodologicamente, pelo enfoque das tirinhas, por serem destaque nas atividades de leitura e de gramática. Observamos que: 
A. 19 das 73 tirinhas (26\% aproximadamente) são tratadas sem levar em consideração a situação da qual emergiram, apenas como pretexto para a abordagem de algum tópico da tradição gramatical;

B. 9 das 73 tirinhas ( $12 \%$ aproximadamente) são utilizadas como pretexto para o ensino de gramática tradicional, porém trazem, nas atividades a elas associadas, em segundo plano, uma ou duas questões que auxiliam a leitura do gênero;

C. 45 das 73 tirinhas ( $61 \%$ aproximadamente) são tratadas a partir de considerações que apenas se aproximam do tratamento como gêneros discursivos, sem explorar de maneira mais consistente suas características, e/ou abordam uma ou outra questão de leitura mais relevante. Dentre elas:

-27 (37\% aproximadamente) são focalizadas em questões voltadas exclusivamente para leitura e interpretação do gênero;

- 18 (24\% aproximadamente) associam leitura e interpretação do gênero, vinculadas com alguma abordagem gramatical, ou seja, a gramática é abordada a serviço da construção do gênero.

\subsection{1. “A Mão QUE Não AlCANÇA” (OU “O PÉ QUE ESMAGA”)}

A condução dada à leitura de 28 das tirinhas presentes no livro não corresponde à proposta teórica de trabalho explicitada pelos autores no manual do professor, e 45 delas apenas se aproximam dessa proposta.

Vejamos a tirinha da figura I, tirada do LD, que evidencia (i) a artificialização do gênero: 
3. Leia esta tira, de Laerte:

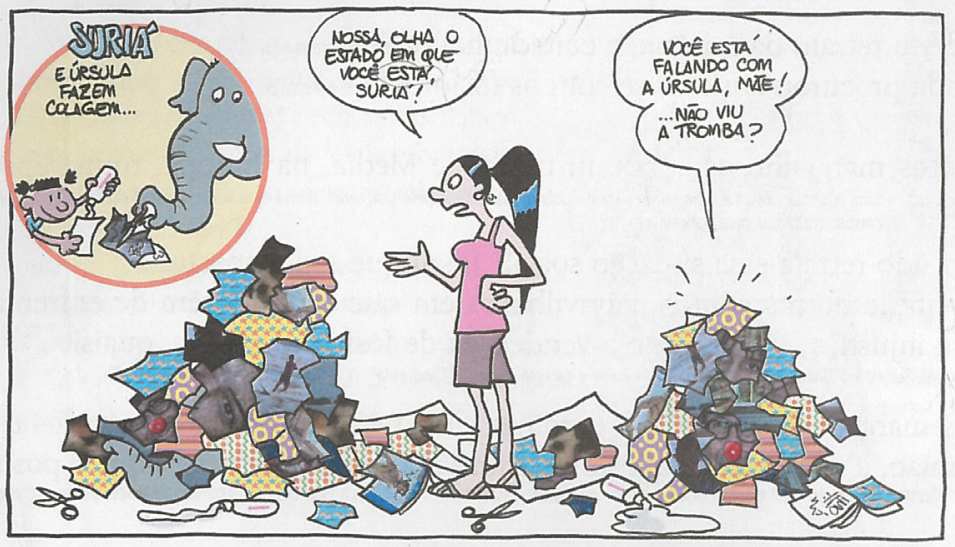

$\mathrm{Na}$ fala de Suriá, de que tipo são as frases que ela emprega? A primeira é exclamativa, e a outra, interrogativa.

Figura I: Tirinha de Laerte

A tirinha de Laerte evidencia, no contexto, que a menina Suriá e um elefante (Úrsula) estão fazendo colagem utilizando papéis, tesoura, tubos de cola. Nota-se que o primeiro balão (legenda), caracterizado de cor diferente da dos outros balões, tem como propósito indicar quem são as personagens, evidenciando a ação: "Suriá e Úrsula fazem colagem”. No contexto dado pelo texto, a desorganização é tanta que as personagens ficam escondidas no meio dos papéis e outros materiais. A mulher dirige-se ao "amontoado de materiais" e conversa com Suriá, mas quem está lá é Úrsula (a elefanta), o que é indicado pelo pedacinho da tromba que aparece no desenho.

Há elementos da imagem associados à escrita verbal dos balões que possibilitam construir os significados; no entanto, o LD apenas usa o texto para perguntar sobre os tipos de frases que a tirinha emprega: interrogativa, exclamativa, etc. Não se explora o contexto, a intencionalidade discursiva vinculada ao propósito de promover humor, o caráter de construção que está vinculado ao acionamento das estruturas linguísticas verbais e não verbais. Pode-se dizer que o gênero, ao ser abordado pelo LD, perdeu sua significação, sua totalidade, não houve interação, muito menos se buscaram as situações de produção ou comunicacionais das quais emergem esse gênero. 
A figura II expõe uma tirinha que serve, no LD focalizado, apenas (ii) como pretexto para o ensino de tópicos da gramática normativa e traz, em segundo plano, uma questão relacionada ao desenvolvimento da habilidade de leitura: 4. Leia a tira ao lado, de Fernando
Gonsales.
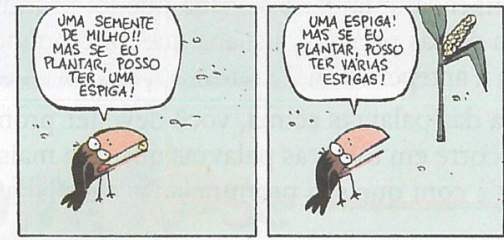

Em certos contextos, a palavra um é numeral; em outros, artigo indefinido. É numeral, pois indica quantidade

a) Na tira acima, nas expressões "uma semente" e "uma espiga", uma é numeral ou é artigo?

b) Por que a tira é engraçada?

Porque mostra que a excessiva ambiç̣̆o do corvo

provocou a morte dele.

\section{Figura II: Tirinha de Fernando Gonsales}

A tira de Fernando Gonsales mostra o pássaro que acha uma semente de milho; ao invés de comê-la, prefere plantar, e, pela ganância, resolve formar a plantação de milho. Envolvido na grande produção, não se alimenta e morre esperando por mais sementes.

Nos dois primeiros quadrinhos, a personagem conversa consigo mesma; no terceiro não há falas. E a imagem (o não verbal) se encarrega de dizer o que aconteceu. Embora houvesse a possibilidade de explorar tais aspectos, as perguntas feitas pelo LD são voltadas para a tradição gramatical: busca-se averiguar a classificação dos pronomes indefinidos. São comuns, em situações escolares, questões que solicitam a classificação dos termos: numeral ou artigo?; pronome do caso reto ou do caso oblíquo?; etc.

Somente na letra (b), em segundo plano, questiona-se sobre a construção do humor, remetendo à leitura, mas o aluno tem que responder de forma intuitiva, sem nenhum direcionamento para questões do gênero textual, para os recursos linguísticos que possibilitam a sua construção. Há uma tentativa de alcançar o leitor, à medida que se questiona de maneira intuitiva sobre algo central para o gênero (a produção do humor).

Como observamos, inserir os diversos gêneros no material didático não garante que estes serão tratados como gêneros. $\mathrm{O}$ que vai determinar seu uso em sala de aula é a forma como ele é abordado. Trata-se de considerar os elementos externos ao texto, 
ou seja, elementos da situação de produção que interagem com os elementos internos e participam da construção do sentido do texto. Claro que não podemos descartar toda uma construção que é a gramática da língua, mas é necessário inseri-la no ensino em função do que é relevante para a leitura e para a escrita, e nunca como um fim.

A tirinha traz consigo diversos elementos para a representação do humor (ou do trágico): as palavras, os personagens, a sucessão de acontecimentos, linguagem e fala complementando-se. Porém pouco disso é considerado. Podemos dizer que houve um apagamento de informações e conhecimentos do gênero. Aqui, torna-se central a afirmação de Neves (2013):

[...] a atenção só vai para a rotulação, identificação, subclassificação, e com a frase arrancada do texto, como se o texto fosse peça morta, simples registro gráfico extenso do qual se pode tirar um ou outro pedacinho, para praticar o esporte de dar nome a certas palavras que nele ocorrem.

Perde-se a oportunidade de levar o aluno a conhecer o gênero, evidenciando os dizeres implícitos e explícitos, considerando os meios de produção e de circulação, questionando a respeito do tema, dos objetivos, da estrutura, da linguagem (verbal ou não verbal), do contexto. Não se dá valor a perguntas que auxiliariam o aluno a construir sentidos; a relacionar o texto com sua vida, tomando por base o contexto evidenciado; a criar problemas e solucioná-los; a induzir o sujeito à reflexão. Concordamos com Lopes-Rossi (2005, p. 74) quando ela fala da necessidade de um nível de conhecimento do gênero discursivo que permita

[...] uma série de inferências, por parte do leitor, para a escolha vocabular, o uso de recursos linguísticos e não linguísticos, a seleção de informações presentes no texto, a omissão de informações, o tom e o estilo, entre outros. São comentários que proporcionam aos alunos, ainda que de forma gradual, a percepção da relação dinâmica entre os sujeitos e a linguagem e a percepção do caráter histórico e social do gênero discursivo em estudos [...].

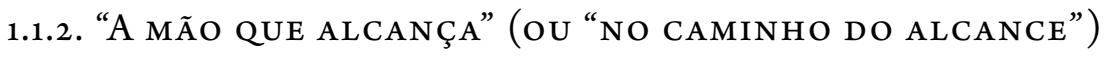

A figura III representa um trabalho mais produtivo, que parece alcançar mais o leitor: 


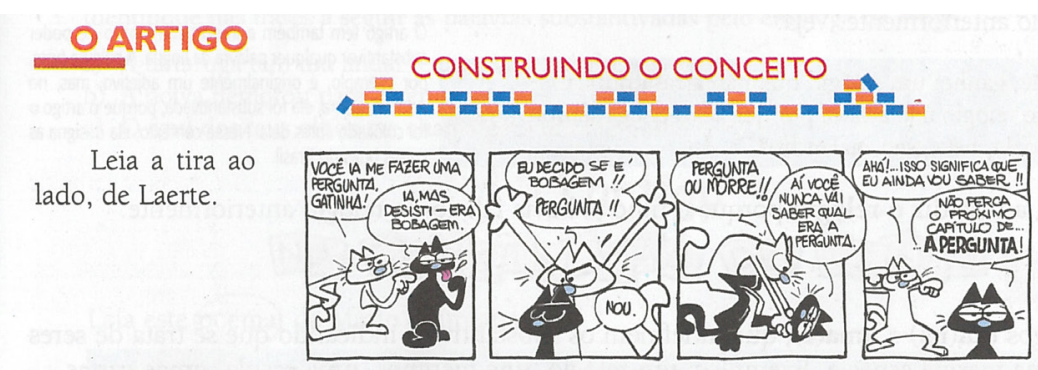

5. Por que o gato ficou bravo com a gatinha?

Porque a gatinha desistiu de fazer-lhe uma pergunta por ter achado que era bobagem, e o gato, curioso, não se conformou com isso.

2. No 1: quadrinho, o gato diz: "Você ia me fazer uma pergunta, gatinha!". No 3 quadrinho, a gatinha diz: "Aí você nunca vai saber qual era a pergunta".

a) No 19 quadrinho, o gato fala de uma pergunta qualquer ou de uma pergunta determinada?

b) E a gatinha no 39 quadrinho? A gatinha fala de uma pergunta determinada, ou seja, aquela pergunta que ela ia fazer ao gato, mas nāo fèz.

3. No último quadrinho, a gatinha diz: "Não perca o próximo capítulo de... ...A pergunta!".

a) O que ela dá a entender com essa frase? Que aquela história terá continuaçāo.

b) Considerando o comportamento do gato, por que a gatinha acha isso? $\begin{aligned} & 0 \text { gato continua curioso e tem esperança } \\ & \text { de saber qual éa pergunta }\end{aligned}$

Figura III: Tirinha de Laerte - Cereja e Magalhães (2009, p. 151)

As atividades exploram a leitura que o aluno fará do texto, aliada a aspectos gramaticais (no caso, pronome indefinido e definido), o que significa certo avanço na forma de tratamento tradicionalmente dada aos textos em geral. Nesse caso, $o$ estudo dos artigos relaciona-se ao próprio entendimento dos quadrinhos e, por isso, faz sentido abordar esse tópico gramatical.

Contudo, para explorar o gênero, seria produtivo abordar os recursos de pontuação e gráficos que possibilitem ao leitor fazer referência a falas em tom muito alto, além da relação intertextual que os textos mantêm com as telenovelas (narradas em capítulos) para construir o sentido. Esse dado representa as 45 abordagens que consideramos mais próximas à proposta do livro, o que corresponde, felizmente, a mais ou menos $61 \%$ das ocorrências.

Das 75 tirinhas analisadas, para 27 são propostas questões exclusivamente de leitura e de interpretação de texto, sem abordagem gramatical. É relevante salientar que apenas nas seções do livro dedicadas ao ensino de leitura/produção de histórias em quadrinhos não é sugerida atividade ou reflexão voltada à tradição gramatical. Contudo, não se trabalham aspectos linguísticos que poderiam auxiliar a interpretação, como, por exemplo, intencionalidade discursiva com vistas a uma dimensão 
comunicacional do gênero, intertextualidade da tirinha com outros textos, leitura. É o caso da figura IV:

\section{Semântica? e discurso}

1. Leia a tira:
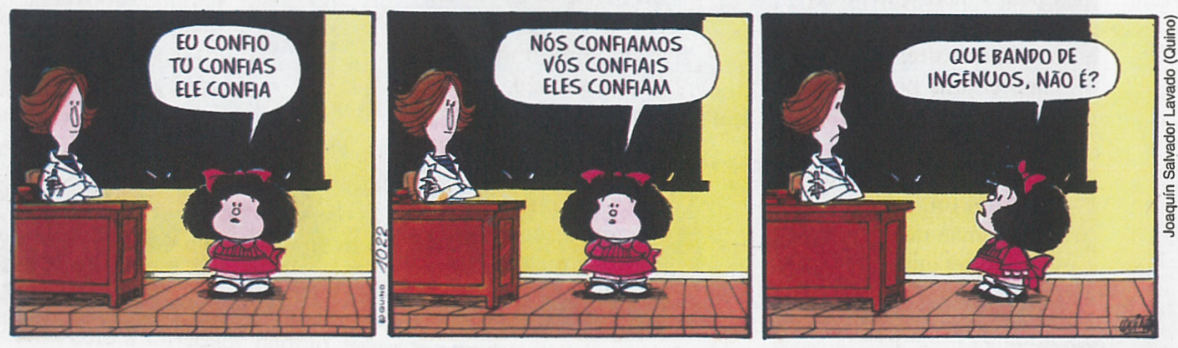

(Quino. O irmãozinho da Mafalda. São Paulo: Martins Fontes, 1999. p. 39.)

A tira apresenta uma situação de sala de aula.

a) O que as personagens estão fazendo nos dois primeiros quadrinhos? Mafalda conjuga o verbo confiar no presen-

b) No último quadrinho, Mafalda faz um comentário. Relacione-o com a situação anterior e responda: Por que esse comentário provoca humor?

Figura IV: Tirinha de Quino - Cereja e Magalhães (2009, p. 222)

A pergunta (a) refere-se à situação típica de aula de gramática tradicional: a aluna conjugando verbos para a professora. No último quadrinho, o clima é quebrado: Mafalda atribui sentido para aquilo que a professora espera que ela repita mecanicamente. Para responder a questão (b), o aluno tem de perceber essa quebra de expectativa, o que desencadeia o humor.

Embora o manual do livro do professor preconize a abordagem funcional da gramática, apenas 18 das 45 (24\% aproximadamente) tirinhas estão voltadas para exercícios que contemplam timidamente essa abordagem, como no exemplo da figura V: 


\section{EXERCICIOS}

Leia a tira a seguir, de Laerte, para responder às questões de 1 a 3
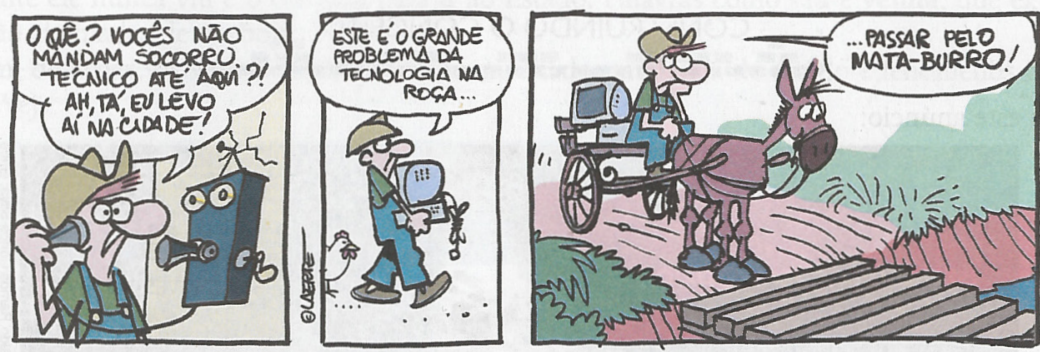

1. No 1 ? quadrinho:

a) Com quem a personagem está falando por telefone? Com alguém de um serviço técrico de manutençăo ou conserto de computadores.

b) Qual é a função da expressão o quê no início da fala desse quadrinho? Demonstrar surpresa, incredulidade.

c) Por que a personagem empregou o pronome vocês no plural?

Como forma de se referir a toda a empresa que presta o serviço de manutenção ou conserío de computadores.

2. A personagem contrapõe dois espaços: a cidade e a roça. No 19 quadrinho:
a) Que palavra se refere à roça? aqui
b) Que palavra se refere à cidade? ai

3. No 2: quadrinho, a que se refere o pronome este: à inexistência de socorro técnico para computadores na

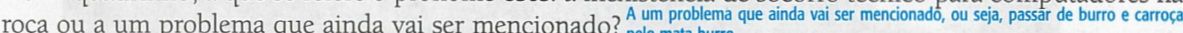

Professor: As respostas são pessoais e há mais de uma resposta possivel na maioria das situaçoes. 0 importante é que o aluno perceba que as escollhas podem tornar o texto coerente ou nảo, coeso ou não. As palavras originais do texto estão colocadas como resposta apenas como referência.

Figura V: Tirinha de Laerte - Cereja e Magalhães (2009, p. 213)

Esta atividade estabelece uma relação entre a leitura e o ensino gramatical, ao tentar chamar a atenção para as funções de "o quê" e "vocês". A questão 3 é muito interessante, por sugerir que o aluno recupere o referente do pronome demonstrativo "este", trazendo à tona possibilidades de interpretação e de recuperação da situação humorística.

Apesar de explorar elementos gramaticais de forma significativa, sem desvincular do sentido que propiciam ao texto, a atividade deixou de lado a reflexão a respeito dos significados de elementos específicos do contexto rural dado pela tirinha, como "mata-burro", que contrasta com novas tecnologias da era do computador. No entanto, as questões são encaminhadas de tal modo que não "esmagam" as possíveis leituras e, assim, é bem provável que a discussão do significado de "mata-burro" 
venha à tona na sala de aula, principalmente nas escolas urbanas, cujos alunos não têm familiaridade com o objeto.

\section{Algumas Reflexões: em busca de uma mão QUe Sempre alCanCe}

Trabalhar gêneros aliados a conteúdos gramaticais é uma questão que envolve reflexão de seus usos, através do exercício da linguagem. Para Neves (2013, p. 151), o lugar de observação que temos disponível se refere aos textos falados e escritos, baseados na própria atividade linguística de que participamos, isto é, na produção e na leitura, ou seja, na interação - "afinal, a gramática rege a produção de sentido". Entendemos que trabalhar de fato com gêneros discursivos na escola significa não isolar a leitura do ensino gramatical, mas sempre aliá-la à construção dos sentidos, atentando-nos às situações de comunicação, ao contexto interacional: "quem é que fala, para quem, querendo dizer o quê, conseguindo ou não ter recuperada a sua intenção, etc." (NEVES, 2010, p. 175), ou seja, a tudo que compõe a sua significação.

Refletir a respeito do uso e da prática da linguagem seria, para Franchi (1987, p. 6), um exercício de promover a criatividade e o pensamento crítico, já esquecido e/ ou confundido pelas nossas escolas e professores, que acreditaram (e/ou acreditam ainda!) "que a criatividade estava só em outro lugar que não a linguagem verbal. Nas manifestações gestuais, na expressão corporal, no desenho livre, etc.". Muito diferente de um lugar de opressão e regra (de "esmagamento"), a gramática seria, para o autor, uma atividade de construção exploratória, sujeita a reformulações na medida do próprio processo de desenvolvimento do ser humano, um ser "imaturo, inacabado, atravessado pela história" e participante de um contínuo processo de construção - a própria e a dos outros - à medida que reutiliza suas vivências, experiências para pensar, modificar e construir o presente de maneira ativa e interferente. Não perder, no exercício da leitura, os significados dos textos e, além disso, usar o conhecimento gramatical a favor do entendimento desses significados, como propõem as últimas questões aqui analisadas, pode ser uma importante contribuição para a formação de leitores críticos (e criativos).

Observamos que, mesmo nas atividades mais interessantes que levam à exploração das leituras possíveis, não há uma integração com os trabalhos voltados para a estrutura da língua. Quando se faz uso das tirinhas para abordar questões gramaticais, o principal, a leitura, é ignorado: o aluno consegue responder ao que 
se solicita, sem ter lido o texto, de fato, sem ter construído qualquer sentido para ele, como mostra o primeiro exemplo que apresentamos na seção 1.1.1.

Tanto a observação das aulas e as conversas com a docente (disponibilizada pela pesquisa paralela a esta) quanto o caderno dos alunos revelam que a atenção maior no contexto escolar é dada às atividades que seguem a tradição gramatical, ainda que elas sejam a minoria no livro didático, e não para aquelas que, de fato, tentam fazer um trabalho tomando o gênero como eixo principal. Muito provavelmente porque nem o professor que está na sala de aula, nem aqueles envolvidos com a produção e a divulgação de materiais didáticos (que tentam atender às diferentes demandas) relacionam de forma plena as teorias linguísticas que envolvem o gênero do texto/discurso com a prática pedagógica.

Nesse sentido, torna-se de fundamental importância para estudantes de Letras e profissionais em formação continuada analisar como estão sendo aplicadas as propostas que preconizam um trabalho com os diversos gêneros. Compreendemos, assim como Bunzen (2007), que o material didático seja um gênero complexo devido às suas intercalações e composições, marcadas pelos seus aspectos gráfico-editoriais (cores, imagens, diagramações e boxes), e reconhecemos que tenha evoluído em qualidade nas últimas décadas, concentrando-se mais nas funções sociais dos sujeitos. Ainda assim, as marcas da tradição são muito evidentes, principalmente quando se desvincula o ensino de gramática das questões de leitura e de interpretação.

Brum (2013, p. 33), no trecho usado como epígrafe, fala sobre as palavras, que ela retoma de memória, do psicanalista Hélio Pellegrino em uma entrevista com Clarice Lispector: "A gente no fundo tem medo de nascer, pois nascer é saber-se vivo - e, como tal, exposto à morte".... A jornalista lembra essa frase ao se deparar com o livro de clichês de Werneck e, com base nela, reforça que escrever e criar constitui uma experiência radical de nascimento. Ela considera que, ao colecionar clichês, o autor chama "a atenção para as inúmeras possibilidades de nascimento que perdemos quando repetimos um lugar comum em vez de uma combinação de palavras que só nós podemos fazer" (p. 33), pela singularidade do nosso olhar.

Parece que no ensino informado pela tradição gramatical - fixado em frases isoladas do contexto e das intenções com que foram pronunciadas - os trechos das tirinhas, que interessam apenas em função da exemplificação de elementos da tradição gramatical, como é o caso de alguns exemplos aqui expostos, funcionam como os clichês: há um esvaziamento de sentido. Reproduz-se por tradição, por costume. Alcançar o leitor, construir de fato o leitor (um dos principais objetivos do ensino de língua materna) 
é correr o risco de se perder, ao tentar fugir do que é corriqueiro, do que faz parte da tradição. É risco para os editores dos materiais didáticos, que passam pelas escolhas; é risco para os docentes, cujo lugar de controle dado pela tradição é desestabilizado.

Mais fácil repetir aquilo que vem pronto, do que arriscar-se na elaboração de outra condução, de outras combinações de palavras; mais fácil do que tentar perceber a lógica nas palavras do outro, veiculada pelos gêneros discursivos. Isso faz lembrar as palavras de Proust (2006, p. 23), quando (tratando de assunto diverso) fala do esforço humano por garantir um lugar comum, cimentado por certezas: “a [...] imobilidade das coisas que nos cercam talvez lhe seja imposta por nossa certeza de que essas coisas são elas mesmas e não outras, pela imobilidade de nosso pensamento perante elas”.

Priorizar o raciocínio da tradição gramatical incide no risco forte de "esmagamento" do leitor - e os números oficiais de analfabetismo funcional revelam que isso é realidade. $O$ problema de escrita e de leitura dos alunos, como evidenciam os professores com os quais dialogamos, parece ter uma amplitude muito maior que aquela apresentada nos limites do desempenho do próprio aluno. Continuaremos a insistir em deslocar o olhar para outros elementos (aparentemente insignificantes) que fazem parte da complexidade que caracteriza a sala de aula, como é o caso da condução da leitura das tirinhas.

\section{REFERÊNCIAS}

BAKHTIN, Mikhail. Os gêneros do discurso. In: BAKHTIN, Mikhail. Estética da criação verbal. $4^{\text {a }}$ ed. São Paulo: Martins Fontes, 2003. (1992, $1^{\mathrm{a}}$ ed.).

BRASIL, Ministério da Educação e Desporto. Parâmetros Curriculares Nacionais. Introdução aos parâmetros curriculares nacionais. Brasília: MEC/SEF, 1997.

. Parâmetros Curriculares Nacionais. $3^{\circ}$ e $4^{\circ}$ ciclos do ensino fundamental. Brasilia: MEC/ SEF, 1998.

BRUM, Eliane. Vida de clichê. In: BRUM, Eliane. A menina quebrada e outras colunas de Eliane Brum. Porto Alegre: Arquipélago, 2013.

BUIN, Edilaine. A gramática a serviço do desenvolvimento da escrita. Revista Brasileira de Linguística Aplicada, Belo Horizonte, v. 4, n. 1, p. 155-171, 2004.

BUZEN, Clécio. O livro didático de português como gênero do discurso: Implicações teóricas e metodológicas. In: Simpósio Sobre o Livro Didático de Língua Materna e Língua Estrangeira SILID, 1 - 3 de agosto de 2007, Rio de Janeiro: I Silid, 2005.

CEREJA, Willian Roberto; MAGALHÃES, Thereza Cochar. Português: linguagens, $6^{\circ}$ ano. $5^{\mathrm{a}}$ ed. reform. São Paulo: Atual, 2009.

FIORIN, José Luiz. Introdução ao pensamento de Bakhtin. São Paulo: Ática, 2006. 
Tirinhas em situações de ensino e o alcance do leitor

FRANCHI, Carlos. Criatividade e gramática. Trabalhos em Linguística Aplicada, Campinas, n. 9, p. $5-45,1987$.

LOPES-ROSSI, Maria Aparecida Garcia. Gêneros discursivos no ensino de leitura e produção de textos. In: KARWOSKI, Acir Mário; GAYDECZKA, Beatriz; BRITO, Karim Siebeneicher (Org.). Gêneros textuais: reflexões e ensino. Palmas; União da Vitória, PR: Kaygangue, 2005.

MENDONÇA, Marcia. Ciência em quadrinhos: recurso didático em cartilhas educativas. $223 \mathrm{ff}$. Tese

(Doutorado em Linguística) - Universidade Federal de Pernambuco, Recife, PE, 2008.

NEVES, Maria Helena M. Que gramática estudar na escola. São Paulo: Contexto, 2004.

. Ensino de língua e vivência de linguagem. São Paulo: Contexto, 2010.

. A gramática: conhecimento e ensino. In: NEVES, Maria Helena M. Que gramática estudar

na escola. $4^{\mathrm{a}}$ ed., $1^{\mathrm{a}}$ reimp. São Paulo: Contexto, 2013.

PROUST, Marcel. No caminho de Swann. São Paulo: Globo, 2006.

SCHEUWLY, Bernard; DOLZ, Joaquim. Os gêneros escolares - das práticas de linguagem aos objetos de ensino. In: SCHEUWLY, Bernard; DOLZ, Joaquim. Gêneros orais e escritos na escola. Campinas: Mercado de Letras, 2004.

SIGNORINI, Inês (Org.). Significados da inovação no ensino de Língua Portuguesa e na formação de professores. Campinas: Mercado de Letras, 2007.

SOUZA, C. H. de; SANTOS, V. dos. Gênero textual: tirinha - características e funcionalidade social. $\mathrm{Em} \mathrm{GT}_{7}, 2013$.

\section{SOBRE AS AUTORAS}

Edilaine Buin é graduada em Letras, Mestre e Doutora em Linguística pela Universidade Estadual de Campinas (UNICAMP), com pós-doutorado pela Universidade de São Paulo (USP). É professora adjunta da Universidade Federal da Grande Dourados (UFGD), onde atua na graduação e no Programa de Pós Graduação em Linguística Aplicada. É autora do livro A escrita na escola: a construção da coerência textual e Aquisição da Escrita: coerência e coesão.

E-mail: edilainebuin@gmail.com

Bianca Estefani Meneguini é graduanda em Letras da Universidade Federal da Grande Dourados (UFGD). É bolsista do PIBID-Letras-UFGD e participante do Programa Institucional Voluntário de Inciação Científica.

E-mail: biancameneguini@hotmail.com

Recebido em 02 de setembro de 2015 e aprovado em 17 de janeiro de 2016. 